\title{
Respon Penggunaan Zat Perangsang Tumbuh Sintetik Dan Alami Pada Petumbuhan Stek Tanaman Hias Lidah Mertua (Sansevieria spp)
}

\section{Response Using Synthetic Growth And Natural Growth In Plant Ornamental Crops Cultivation (Sansevieria spp)}

\author{
Muhamad Hadi Reka Utama, Syahbudin Hasibuan, dan Maimunah \\ Fakultas Pertanian, Universitas Medan Area, Indonesia \\ *Corresponding author: E-mail: hadiumafp@gmail.com
}

\begin{abstract}
Abstrak
Penelitian bertujuan untuk mengetahui respon tanaman lidah mertua terhadap hormon auxin dan ekstrak tunas air kakao yang berasal dari cupon atau tunas air kakao yang biasanya tidak dimanfaatkan pada pembudidayaan tanaman kakao. Metode penelitian menggunakan Rancangan Acak Lengkap ( RAL ) faktorial dengan 2 ulangan. Faktor yang diteliti adalah ekstrak tunas air kakao dengan bahan baku cupon dengan 3 taraf, dan hormon auxin dengan merek dagang atonik dengan 3 taraf. $\quad$ Dari hasil penelitian diperoleh hasil sebagai berikut, adanya pengaruh berbagai perlakuan penggunaan berbagai konsentrasi Zat Perangsang Tumbuh Sintetik dan Alami terhadap pertumbuhan stek tanaman hias Lidah Mertua menunjukkan persentasi hidup yang nyata 91,7\% hidup hingga 12 minggu.Tidak ada pengaruh terhadap pertumbuhan yang menunjukan beda nyata dan sangat nyata dalam parameter yang diamati dari setiap penggunaan berbagai konsentrasi ZPT sintetik dan alami terhadap pertumbuhan stek tanaman hias lidah Mertua.
\end{abstract}

Kata Kunci: ZPT Alami, Stek, Lidah Mertua

\begin{abstract}
The aim of this research is to know the response of tongue-in-law plant to auxin hormone and cocoa water shoot extract from coconut shoot or cupon which is not used in cocoa cultivation. The research method used Factorial Randomized Design (RAL) with 2 replications. The factors studied were cocoa water shoot extract with cupon raw material with 3 levels, and auxin hormone with atonik trademark with 3 levels. From the research results obtained the following results, the influence of various treatments of the use of various concentrations of Synthetic Growth and Natural Growth Additives to the growth of ornamental plant cuttings Tongue Mertua showed a real live percentage of 91.7\% live up to 12 weeks. There is no effect on the growth of different shows real and very real in the observed parameters of each use of various concentrations of synthetic and natural ZPT on the growth of Orthopedic crop planting cuttings.
\end{abstract}

Keywords: Natural ZPT, Cuttings, Aloe Vera

How to Cite: Utama M. H. R, Syahbudin H., dan Maimunah, (2016), Respon Penggunaan Zat Perangsang Tumbuh Sintetik Dan Alami Pada Petumbuhan Stek Tanaman Hias Lidah Mertua (Sansevieria spp ), Jurnal Agrotekma, 1 (2): 81-91 


\section{PENDAHULUAN}

Sansiviera merupakan salah satu jenis tanaman hias yang cukup digemari dikalangan parahobiis tanaman hias dan merupakan tanaman yang sudah tak asing lagi dimasyarakat Indonesia. Tanaman yang dikenal sebagai lidah mertua ini memiliki banyak penggemar di Indonesia bahkan di dunia. Sansiviera memiliki banyak varietas yang beragam, sebagai tanaman hias sansevirasering digunakan sebagai elemen penghias taman dan teras rumah.(Suci. 1991).

Tanaman ini dikenal mampu menyerap polusi udara dan menghilangkan radiasi lingkungan, sehingga tidak mengherankan jika tanaman hias sansevieria banyak dimanfaatkan sebagai tanaman penyegar dalam ruangan. Sansevieria atau lidah mertua merupakan salah satu tanaman istimewa lantaran mempunyai kemampuan sebagai penyerap racun (polutan) di udara. Berbagai jenis racun yang mampu diserap oleh Sansevieria antara lain karbonmonoksida, nikotin, benzene, formaldehyde, trichloroethylene, hingga dioksin.Berdasarkan penelitian Badan Antariksa Amerika Serikat (NASA; National Aeronautics and Space Administration), sansevieria atau lidah mertua mempunyai kemampuan menyerap hingga 107 jenis unsur berbahaya (racun atau polutan). Riset lainnya menyimpulkan bahwa dengan 5 helai daun sansevieria dewasa mampu menyerap dan membersihkan ruangan seluas $100 \mathrm{~m}^{3}$ dari berbagai jenis polutan (Novik, 2013).

Secara ekonomis, menjual produk sansevieria murah memang untung, tapi Sansiviera punya pasar yang jauh menguntungkan. Selain dimanfaatkan sebagai tanaman hias dan tanaman yang berguna sebagai penyerap antioksidan dan zat racun, tanaman Sansivieria jenis Cylindrica, Trifasciata. Serat daunnya, panjang, kuat, mengkilap, elatis dan tak rapuh bila terkena air. Karena keunggulan sifat-sifat serat daunnya digunakan sebagai bahan baku serat industri tekstil di beberapa negara seperti Cina dan Selandia baru(Syamsul, 2008).

Perbanyakan tanaman lidah mertua melalui biji sangat sulit dan jarang dilakukan selain jarangnya terjadi penyerbukan dikarenakan bunga jantan dan bunga betina yang tidak terdapat dalam satu kuntum bunga dan juga mudahnya gugur kuntum sebelum sebelum terjadinya proses penyerbukan atau matangnya serbuk sari, selain itu penyerbukan melalui dengan bantuan serangga juga tak banyak membantu dalam proses terjadinya penyerbukan dikarenakan kuntum bunga yang mudah gugur atau kuntum yang terlalu kecil sehingga membuat serangga penyerbuk sulit untuk hinggap. Selain itu dengan bantuan tangan manusia juga sanggat sulit, selain sulit untuk menentukan waktu matangnya serbuk sari dan kepala putik ketelitian yang sanggat tinggi juga di perlukan dalalm proses penyerbukan bunga jantan dan betina pada tanaman lidah mertua(Sulastiana, 2007).

Tanaman lidah mertua selain dapat diperbanyak melalui biji dapat juga dengan cara stek yang biasa dilakukan dengan cara mengambil bagian daun tanaman lidah mertua dan dipacu pertumbuhan tunas dan akarnya dengan menggunakan ZPT, akan tetapi pertumbuhan tunas akan terhambat bila 
konsentrasi penggunaan Zat Perangsang Tumbuh tidak sesuai atau berlebihan. Terhambatnya pertumbuhan tunas juga bisa terjadi karena energi yang dihasilkan dari metabolisme karbohidrat telah habis digunakan untuk pertumbuhan akar. Hal ini terlihat dari hasil penelitian sebelumnya, yang menunjukkan bahwa semakin tinggi konsentrasi IBA maka jumlah akar yang terbentuk semakin banyak tetapi waktu muncul tunas lebih lama dan persentase setek bertunas lebih rendah. Selain itu juga diduga pemberian IBA dengan konsentrasi tinggi menyebabkan perbandingan auksin yang dikandung menjadi lebih tinggi dibanding sitokinin sehingga pertumbuhan akar lebih dominan dibanding pertumbuhan tunas.Pertumbuhan tunas terbaik dihasilkan oleh aplikasi 0 ppm IBA yang terlihat pada variabel waktu muncul tunas, panjang tunas, jumlah daun tunas, persen setek bertunas, dan bobot basah tunas. Ini menunjukkan bahwa secara genetis sansevieria tidak memerlukan auksin dari luar (Sri Rahmayani. 2007).

Secara umum bahan setek bagian tengah menghasilkan respon terbaik untuk variabel waktu muncul akar, jumlah akar, panjang akar, jumlah tunas, dan bobot basah tunas, namun demikian bahan setek bagian tengah tidak memberikan pengaruh pada waktu muncul tunas, sama halnya dengan setek bagian bawah. Ini sesuai dengan penelitian yang dilakukan olehHardjanti yang menyatakan bahwa setek adenium yang berasal dari bagian tengah menghasilkan pertumbuhan akar lebih baik daripada setek yang berasal dari bagian atas/pucuk. Hal ini diduga karena setek bagian tengah memiliki kandungan karbohidrat yang tinggi daripada setek bagian atas/pucuk. Pada awal penyetekan karbohidrat berperan penting dalam metabolisme tanaman yang menghasilkan energi yang kemudian digunakan untuk pertumbuhan akar (Hardjanti. 2005).

Dari hasil penelitian diketahui bahwa setek bagian atas menghasilkan waktu muncul tunas dan jumlah tunas lebih baik dibandingkan dengan setek bagian pangkal meskipun tidak berbeda nyata dengan setek bagian tengah Ini diduga karena bahan setek bagian atas atau pucuk lebih meristematik, yang artinya sel-sel dalam jaringan sangat aktif membelah sehingga tunas lebih cepat muncul dan tunas yang dihasilkan lebih banyak(Sri Rahmayani. 2007).

Kemampuan setek membentuk akar dan tunas dipengaruhi oleh kandungan karbohidrat dan keseimbangan hormon yang tercermin pada $\mathrm{C} / \mathrm{N}$ rasio diduga bahan setek yang berasal dari bagian tengah memiliki rasio $\mathrm{C} / \mathrm{N}$ yang ideal sehingga memberikan respon yang terbaik. Bahan setek dengan $\mathrm{C} / \mathrm{N}$ rasio yang tinggi akan lebih mudah membentuk akar. $\mathrm{C} / \mathrm{N}$ rasio yang tinggi menunjukkan kandungan karbohidrat atau cadangan makanan yang tinggi yang diperlukan pada awal pertumbuhan akar. Terbentuknya akar pada setek merupakan hal penting, karena untuk kelangsungan hidup setek sangat tergantung pada banyaknya akar yang terbentuk.Awal terbentuknya akar dimulai oleh adanya metabolisme cadangan nutrisi berupa karbohidrat yang menghasilkan energi yang selanjutnya mendorong pembelahan sel dan membentuk sel-sel baru dalam jaringan. Setiap tanaman memiliki kemampuan totipotensi dan diferensiasi sehingga dapat menumbuhkan tanaman 
baru yang utuh.Pembentukan dan pertumbuhan tunas akan terjadi setelah akar terbentuk dengan baik. Setelah primordia akar terbentuk maka akar tersebut segera dapat berfungsi sebagai penyerap makanan dan titik tumbuhnya akan dapat segera menghasilkan zat pengatur tumbuh (sitokinin) yang diperlukan untuk menginduksi tunas. Kandungan karbohidrat bahan setek bagian tengah setelah terbentuk akar dimanfaatkan untuk menumbuhkan tunas. (Salisbury dan Ross, 1995).

\section{METODE PENELITIAN}

Bahan Penelitian yaitu tanaman Lidah Mertua sebagai bahan stek, Atonik, ekstrak tunas air kakao, sekam padi, fungisida Dhitane M-45, pasir, air.

Alat Penelitian yaitu keranjang plastik dengan ukuran $30 \mathrm{~cm}$ x $23 \mathrm{~cm}$ x 10 $\mathrm{cm}$, pisau, cangkul, hands sprayer, gembor, gelas ukur, bambu, kawat, paranet, tepas rumbia, gunting, meteran, timbangan, dan alat-alat tulis.

Percobaan ini dilakukan dengan menggunakan Rancangan Acak Lengkap (RAL) faktorial, untuk melihat respon pertumbuhan bahan stek tanaman lidah mertua (Sanseveria sp) terhadap pemberian Atonik dan ekstrak cupon kakao dengan konsentrasi yang berbeda.

Rancangan Acak Lengkap faktorial dilakukan dengan ulangan 2 kali. Faktor konsentrasi Atonik ( A ).

A0 : Tanpa Atonik $+1000 \mathrm{ml}$ air,

A1 : Atonik $100 \mathrm{ppm}$,

A2 : Atonik $200 \mathrm{ppm}$,

A3 : Atonik 300 ppm.

Faktor konsentrasi Ekstrak cupon kakao(E)

E0: Tanpa ekstrak tanas air $+1000 \mathrm{ml}$ air
E1 : Ekstrak $150 \mathrm{cc}+1000 \mathrm{ml}$ air,

E2 : ekstrak $250 \mathrm{cc}+1000 \mathrm{ml}$ air,

E3 : Ekstrak $350 \mathrm{cc}+1000 \mathrm{ml}$ air

Model umum percobaan Rancangan

Acak Lengkap ( RAL ) Faktorial adalah sebagai berikut :

$$
\text { Yijk }=\mu+\alpha i+\beta j+\sum i j k
$$

Keterangan :

Yijk : Nilai pengamatan

$\mu \quad$ : Nilai rata-rata pengamatan

ai : Pengaruh perlakuan zat

pengatur tumbuh Atonik taraf ke- i

$\beta \mathrm{j}:$ Pengaruh perlakuan Ekstrak tunas air kakao taraf ke-j

$\sum \mathrm{ij} \quad$ : Galat percobaan

Parameter yang diamati pada penelitian ini adalah persentase hidup, berat basah tanaman, bobot basah akar, volume akar, bobot akar kering dan bobot kering tanaman

Percobaan ini dilakukan dengan membuat Shanding house (sungkup) berbentuk segitiga, lebar sungkup 1,2 m dengan panjang $6 \mathrm{~m}$ serta tinggi sungkup 1,2 m. Sungkup dibuat dari paranet, ini bertujuan agar intensitas cahaya dapat masuk, dan di atasnya diberikan naungan agar suhu di dalam Shanding hause tetap terjaga. Serta jarak antara sungkup dan naungan berkisar setengah meter dari atas sungkup. Bahan stek diletakan pada keranjang mini yang telah diberi media pasir dan sekam yang telah disterilisasi.

Media tanam berupa pasir halus dan sekam dengan perbandingan 1:1 yang kemudian disterilisasi dengan cara disangrai, menggunakan wajan besi sampai pasir dan sekam berubah warna. Setelah media didinginkan disemprot dengan fungisida Dhitane M-45, dan juga pada keranjang mini cuci dengan air dan disemprot dengan fungisida.Setelah media 
dan tempat disterilisasi pengisian media ke keranjang mini dilakukan hingga bibir keranjang.

Zat Pengatur Tumbuh Atonik diukur dengan menggunakan gelas ukur dengan jumlah masing-masing 100 ppm, 200 ppm, 300 ppm. Kemudian ZPT dilarutkan ke dalam air Aquades sebanyak $100 \mathrm{ml}$.

Persiapan bahan stek yang diambil dari daun tanaman yang daunnya memiliki warna hijau segar, kemudian daun yang telah diambil dipotong dengan panjang potongan $10 \mathrm{~cm}$. Setelah mendapatkan potongan yang diinginkan sepertiga dari potongan bahan stek direndam dengan larutan yang telah disiapkan. Dengan durasi waktu perendaman yang sama yaitu selama 3 jam. Dengan larutan telah diserap kedalam jaringan daun tanaman lidah mertua.

Penanaman dilakukan pada sore hari setelah penyiapan bahan stek, media yang di siapkan dalam keadaan telah siap tanam, yaitu media yang steril dan pada media tanam di lubangi agar bahan stek tidak mengalami gesekan vertikal dengan media. Bahan stek yang telah direndam selama 3 jam kemudian ditanam pada lubang yang telah disediakan dan disusun sedemikian rupa sesuai dengan jumlah yang telah ditetapkan. Selanjutnya bahan stek ditanam dengan jarak $2 \mathrm{~cm}$ x $5 \mathrm{~cm}$ sedalam $\pm 3 \mathrm{~cm}$.

Persiapan ekstrak tunas air kakao dimulai dengan pembuatan bahan ekstrak yaitu dengan cara mencacah tunas air hingga menjadi potongan-potongan kecil dan halus, lalu cacahan tunas air di masukan kedalam toples bersama dengan gula pasir, gula merah dan air kemudian toples di tutup rapat dan di beri lubang kecil pada tutup toples dan di biarkan selama 2 malam. Kemudian ekstrak tunas air disiapkan dan diukur sesuai dengan takaran yang diinginkan yaitu 150 cc, 250 cc, 350 cc. Kemudian ekstrak dilarutkan dengan air Aquades. Setiap 1 hari sekali ekstrak disemprotkan dengan menggunakan sprayer dengan dosis yang telah ditentukan hingga tanaman basah.

\section{HASIL DAN PEMBAHASAN}

Pengaruh berbagai konsentrasi Antonik dengan dikombinasikan berbagai konsentrasi Ekstrak Tunas Air Kakao dan kontrol pada tanaman Lidah Mertua dilakukan pengamatan terdiri dari persentasi hidup, berat basah tanaman, berat kering tanaman, berat basah akar tanaman, berat kering akar tanaman, volume akar, suhu dan kelembaban. Hasil pengamatan masing-masing parameter disajikan dalam tabel.

Persentase Hidup Tanaman Hias Lidah Mertua (\%)

Data pengamatan persentase hidup tanaman hias lidah mertua dari berbagai konsentrasi antonik dan berbagai konsentrasi ektrak tunas air kakao pada pengukuran minggu ke 1 sampai pengukuran minggu ke 12 disajikan pada lampiran 16 sampai lampiran 21. Tanaman lidah mertua pada umur 1 minggu sampai 4 minggu, persentasi hidup tanaman $100 \%$ hidup, pada umur 5 minggu persentasi hidup tanaman 96,4\%, pada umur 6 minggu sampai 9 minggu persentasi hidup tanaman 93,8\%, umur 10 minggu persentasi hidup tanaman 93,2\%, sedangkan pada umur 11 minggu sampai 12 minggu persentasi hidup tanaman 91,7\%, hal ini terlihat jelas pada Tabel 1. 
Tabel 1. PersentasiHidup Tanaman Lidah Mertua.

\begin{tabular}{|c|c|c|c|c|c|c|c|c|c|c|}
\hline \multirow[b]{2}{*}{ Perlakuan } & \multicolumn{8}{|c|}{ Jumlah Tanaman Hidup } & \multirow[b]{2}{*}{ Total } & \multirow{2}{*}{$\begin{array}{l}\text { Rata- } \\
\text { rata }\end{array}$} \\
\hline & $\begin{array}{l}5 \\
\text { MST }\end{array}$ & $\begin{array}{l}6 \\
\text { MST }\end{array}$ & $\begin{array}{l}7 \\
\text { MST }\end{array}$ & $\begin{array}{l}8 \\
\text { MST }\end{array}$ & $\begin{array}{l}9 \\
\text { MST }\end{array}$ & $\begin{array}{l}10 \\
\text { MST }\end{array}$ & $\begin{array}{l}11 \\
\text { MST }\end{array}$ & $\begin{array}{l}12 \\
\text { MST }\end{array}$ & & \\
\hline A0E0 & 12 & 12 & 12 & 12 & 12 & 12 & 12 & 12 & 96 & 12,0 \\
\hline A0E1 & 11 & 12 & 12 & 12 & 12 & 11 & 11 & 11 & 92 & 11,5 \\
\hline A0E2 & 11 & 12 & 12 & 12 & 12 & 12 & 12 & 11 & 94 & 11,8 \\
\hline A0E3 & 10 & 10 & 10 & 10 & 10 & 10 & 10 & 10 & 80 & 10,0 \\
\hline A1E0 & 12 & 12 & 12 & 12 & 12 & 12 & 12 & 12 & 96 & 12,0 \\
\hline A1E1 & 12 & 12 & 12 & 12 & 12 & 12 & 12 & 12 & 96 & 12,0 \\
\hline A1E2 & 12 & 11 & 11 & 11 & 11 & 11 & 11 & 11 & 89 & 11,1 \\
\hline A1E3 & 12 & 10 & 10 & 10 & 10 & 10 & 10 & 10 & 82 & 10,3 \\
\hline A2E0 & 10 & 11 & 11 & 11 & 11 & 11 & 11 & 11 & 87 & 10,9 \\
\hline A2E1 & 12 & 12 & 12 & 12 & 12 & 12 & 12 & 12 & 96 & 12,0 \\
\hline A2E2 & 11 & 10 & 10 & 10 & 10 & 10 & 10 & 10 & 81 & 10,1 \\
\hline A2E3 & 12 & 11 & 11 & 11 & 11 & 11 & 11 & 11 & 89 & 11,1 \\
\hline A3E0 & 12 & 11 & 11 & 11 & 11 & 11 & 11 & 11 & 89 & 11,1 \\
\hline A3E1 & 12 & 10 & 10 & 10 & 10 & 11 & 11 & 10 & 84 & 10,5 \\
\hline A3E2 & 12 & 12 & 12 & 12 & 12 & 12 & 12 & 11 & 95 & 11,9 \\
\hline A3E3 & 12 & 12 & 12 & 12 & 12 & 11 & 11 & 11 & 93 & 11,6 \\
\hline Total & 185 & 180 & 180 & 180 & 180 & 179 & 179 & 176 & 1439 & \\
\hline Persentase & 96,4 & 93,8 & 93,8 & 93,8 & 93,8 & 93,2 & 93,2 & 91,7 & & \\
\hline Rata-rata & 11,6 & 11,3 & 11,3 & 11,3 & 11,3 & 11,2 & 11,2 & 11,0 & & 11,2 \\
\hline
\end{tabular}

Dari Tabel 1 di atas menunjukan Secara umum bahan stek bagian pucuk bahwa persentasi hidup tanaman hias lidah mertua pada minggu pertama sampai minggu ke empat jumlah tanaman yang hidup adalah 192 pohon (100\%), Pada minggu ke lima tanaman yang hidup 185 pohon $(96,4 \%)$, pada minggu ke enam sampai minggu ke sembilan tanaman yang hidup 180 pohon (93,8\%), pada minggu ke sepuluh dan ke sebelas tanaman yang hidup 179 pohon (93,2\%) dan pada perlakuan ke duabelas tanaman yang hidup 176 pohon (91,7\%). Menurunya persentase hidup disebabkan iklim yang selalu berubah selama proses pertumbuhan dan dipengaruhi intensitas curah hujan yang berubah sehingga suhu dan kelembapan yang tidak teratur, serta dipengaruhi juga oleh asal bahan stek yang menggunakan pucuk tanaman, menghasilkan respon tidak baik untuk variabel waktu muncul akar, jumlah akar, panjang akar, dan bobot basah tanaman, namun demikian bahan stek bagian pucuk tidak memberikan pengaruh pada waktu dengan stek bagian bawah. Ini sesuai dengan penelitian yang dilakukan oleh Hardjanti (2005)

Data pengamatan persentase hidup (\%) tanaman lidah mertua dari berbagai konsentrase zat pengatur tumbuh sintetis (antonik) dan berbagai konsentrasi ekstrak tunas air kakao (alami) di sajikan pada Tabel 1 . Nilai $F$ hitung persentase hidup tanaman lidah mertua pada pengamatan minggu ke-1 sampai dengan minggu ke-12 dengan perlakuan konsentrasi zat perangsang tumbuh sintentis perlakuan alami disajikan pada Tabel 2. 
Tabel 2. Nilai F Hitung Persentase Hidup Tanaman Lidah Mertua dengan Perlakuan ZPT Sintetis dan Alami pada Pengamatan Minggu ke 5 Sampai Minggu ke 12

\begin{tabular}{lllllllllllll}
\hline & & \multicolumn{1}{c}{ F hit } & \multicolumn{1}{c}{ Persentase Tumbuh Pengamatan Ming ke-1 sampai Ming ke-12 } & \\
\cline { 3 - 15 } SK & DB & 6 & 7 & 8 & 9 & 10 & 11 & 12 & \multirow{2}{*}{0,5} & 0,1 \\
& & MST & MST & MST & MST & MST & MST & MST & MST & & \\
\hline Klok & 1 & 3,69 & 0,52 & 0,52 & 0,52 & 0,52 & 1,40 & 0,34 & 0,34 & 4,49 & 8,53 \\
Prk & 15 & 3,47 & 1,51 & 1,51 & 1,51 & 1,51 & 1,40 & 0,73 & 0,73 & 2,35 & 3,41 \\
A & 3 & 6,97 & 0,34 & 0,34 & 0,34 & 0,34 & 0,16 & 0,23 & 0,23 & 3,24 & 5,29 \\
E & 3 & 0,41 & 1,03 & 1,03 & 1,03 & 1,03 & 2,23 & 1,13 & 1,13 & 3,24 & 5,29 \\
AXE & 9 & 3,33 & 2,06 & 2,06 & 2,06 & 2,06 & 1,54 & 0,76 & 0,76 & 2,54 & 3,78 \\
\hline
\end{tabular}

Dari Tabel 2 diatas persentase hidup tanaman lidah mertua dengan perlakuan ZPT sintetis dan alami pada pengamatan minggu ke-1 sampai minggu ke-4 perlakuan tidak nyata baik pada setiap kelompok, sedangkan pada minggu ke-5 perlakuan sangat nyata (A1 100 ppm) dikerenakan $\mathrm{F}$ hitung lebih besar dari pada $\mathrm{F} 0,01$, sehingga pada perlakuan Antonik (F hit:6,97) dan F 0,1 $(5,29)$ dan perlakuan kombinasi nyata sedangkan pada minggu ke-6 sampai pengamatan minggu ke-12persentase hidup tanaman lidah mertua tidak berpengaruh nyata pada perlakuan dan kelompok. Persentase stek hidup daun tanaman lidah mertua (Sansevieria) selama 12 minggusetelah tanam (MST) menunjukkan bahwa ratarata persentase stek hidup pada 5 MST adalah 100\%, 8 MST adalah 99,4\%, dan 12 MST adalah 94,4\% (153 stek berhasil hidup dengan baik dari total162 stek) untuk semua perlakuan zat pengatur tumbuh sintetik Rootone-F dan asal bahan stek (Sulistiana 2007).

Berat Basah Akar Tanama Hias Lidah Mertua (g)

Data pengamatan berat basah akar tanaman hias lidah mertuapada umur 12 minggudisajikan pada Lampiran 1, hasil pengukuran berat basah akar tanaman hias lidah mertua, umur 12 minggu tanaman, menunjukan bahwa perlakuan pemberian (E1) merupakan hasil yang tertinggi $(412,13 \mathrm{~g})$ berbeda nyata dengan perlakuan pemberian (E2) yaitu $(344,25$ g), perlakuan (E0) yaitu $(339,00)$ dan perlakuan (E3) merupakan hasil terkecil $(298,83 \mathrm{~g})$ dan perlakuan pemberian (A0) merupakan hasil yang tertingi $(377,46 \mathrm{~g})$ dengan bedatidak nyata dengan perlakuan lainnya dan perlakuan (A2) merupakan hasil terkecil(314,79g). Hal ini terlihat pada Tabel 3.

Tabel 3. Rata-Rata Hasil Berat Basah AkarTanaman Lidah Mertua pada Perlakuan Ekstrak Tunas Air Kakao Umur 12 Minggu.

\begin{tabular}{llll}
\hline Perlakuan & Rata-rata & 0.05 & 0.01 \\
\hline Eo & $339,00^{*}$ & b & A \\
E1 & $413,13^{*}$ & a & A \\
E2 & $344,25^{*}$ & b & A \\
E3 & 298,83 tn & c & A \\
\hline
\end{tabular}

Keterangan : Angka dengan huruf yang sama pada kolom yang sama tidak berbeda nyata padateraf $5 \%$ (huruf kecil) dan pada taraf 1\% (huruf besar) dengan uji jarak Duncan (DMRT)

\section{Perlakuan Konsentrasi Antonik} berbeda tidak nyata dengan perlakuan berbagai konsentrasi lain. Berdasarkan rata-rata perlakuan konsentrasi antonik terhadap tanaman hias lidah mertua tertinggi terdapat pada perlakuan kontrol $(377,46 \mathrm{~g})$ dan yang terkecil terdapat pada perlakuan A2 $(314,79 \mathrm{~g})$. Dapat dilihat pada Tabel 4 . 
Tabel 4. Rata-Rata Hasil Berat Basah AkarTanaman Lidah Mertuapada Perlakuan Konsentrasi Antonik pada Umur 12 Minggu.

\begin{tabular}{llll}
\hline Perlakuan & Rata-rata & 0.05 & 0.01 \\
\hline Ao & $377,46 \mathrm{tn}$ & $\mathrm{a}$ & $\mathrm{A}$ \\
$\mathrm{A} 1$ & $347,67 \mathrm{tn}$ & $\mathrm{a}$ & $\mathrm{A}$ \\
$\mathrm{A} 2$ & $314,79 \mathrm{tn}$ & $\mathrm{a}$ & $\mathrm{A}$ \\
$\mathrm{A} 3$ & $254,29 \mathrm{tn}$ & $\mathrm{a}$ & $\mathrm{A}$ \\
\hline \multicolumn{2}{r}{ Keterangan : Angka dengan huruf yang sama pada kolom yang } \\
sama tidak berbeda nyata pada teraf 5\% (huruf kecil) dan pada \\
taraf 1\% (huruf besar) dengan uji jarak Duncan (DMRT)
\end{tabular}

Berdasarkan Tabel 4 di atas perlakuan Atonik berlaku tidak nyata terhadap pertumbuhan akar tanaman lidah mertua, hal ini bukan hanya disebabkan konsentrasi Atonik namun lingkungan dan media tanam juga dapat mempengaruhi pertumbuhan akar pada tanaman lidah mertua. Menurut Dwijoseputro (1988) walaupun setek mendapat perangsang untuk pertumbuhan akar,tapi kalau faktor lingkungan dan media tumbuh tidak mendukung maka akar juga tidak akanberkembang dengan baik. panjang pendeknya akar dipengaruhi juga oleh rintangan yang ditemui oleh akar dalam menembus tanah, bila akar tidakmampu menembus tanah, maka bentuk akar jadi lebih pendek.

\section{Berat Kering Akar Tan. Lidah Mertua (g)}

Data pengamatan berat kering akar tanaman hias lidah mertua pada umur 12 minggu dapat dilihat lebih jelas pada Lampiran, tertera tabel pengukuran berat basa akar tanaman hias lidah mertua, umur 12 minggu tanaman, pengukuran menunjukan bahwa perlakuan pemberian (E0) merupakan hasil yang tertinggi $(191,79 g)$ dengan tidak nyata dengan perlakuan pemberian (E1) dan perlakuan (E2) dan perlakuan (E3) merupakan hasil terkecil (172,38 g) dan perlakuan pemberian (A3) merupakan hasil yang tertingi $(196,83 \mathrm{~g})$ dengan bedatidak nyata dengan perlakuan lainnya dan perlakuan (A2) merupakan hasil terkecil $(166,71 \mathrm{~g})$. Untuk lebih jelas, di bawah ini tertera tabel Rata-rata hasil berat basah akar tanaman hias lidah mertua pada umur 12 minggu.

Tabel 5. Rata-Rata Hasil Berat Kering Akar Tanaman Lidah Mertua pada Perlakuan Ekstrak Tunas Air Kakao Umur 12 Minggu.

\begin{tabular}{llll}
\hline Perlakuan & Rata-rata & 0.05 & 0.01 \\
\hline Eo & $191,21 \mathrm{tn}$ & $\mathrm{a}$ & $\mathrm{A}$ \\
E1 & $187,42 \mathrm{tn}$ & $\mathrm{a}$ & $\mathrm{A}$ \\
E2 & $186,42 \mathrm{th}$ & $\mathrm{a}$ & $\mathrm{A}$ \\
E3 & $172,38 \mathrm{tn}$ & $\mathrm{a}$ & $\mathrm{A}$ \\
\hline
\end{tabular}

Keterangan : Angka dengan huruf yang sama pada kolom yang sama tidak berbeda nyata pada teraf $5 \%$ (huruf kecil) dan pada taraf 1\% (huruf besar) dengan uji jarak Duncan (DMRT)

Perlakuan Konsentrasi Antonik berbeda tidak nyata dengan perlakuan berbagai konsentrasi lain. Berdasarkan rata-rata perlakuan konsentrasi antonik terhadap tanaman hias lidah mertua tertinggi terdapat pada perlakuanA3 $(196,83 g)$ dan yang terkecil terdapat pada perlakuan A2 $(166,71 \mathrm{~g})$. Dapat dilihat pada Tabel 6 dibawah ini.

Tabel 6. Rata-Rata Hasil Berat Kering Akar Tanaman Lidah Mertua pada Perlakuan Konsentrasi Antonik pada Umur 12 Minggu.

\begin{tabular}{llll}
\hline Perlakuan & Rata-rata & 0.05 & 0.01 \\
\hline Ao & 189,21 tn & a & A \\
A1 & 185,25 th & a & A \\
A2 & 166,71 th & a & A \\
A3 & 196,83 tn & a & A \\
\hline
\end{tabular}

Keterangan : Angka dengan huruf yang sama pada kolom yang sama tidak berbeda nyata pada teraf $5 \%$ (huruf kecil) dan pada taraf 1\% (huruf besar) dengan uji jarak Duncan (DMRT)

\section{Berat Basah Tanaman Lidah Mertua (g) Data pengamatan berat basah tanaman lidah mertua pada umur 12}


minggu dapat dilihat lebih jelas pada tabel pengukuran berat basa tanaman hias lidah mertua, umur 12 minggu tanaman, pengukuran menunjukan bahwa perlakuan pemberian (E3) merupakan hasil yang tertinggi $(15,73 g)$ dengan tidak nyata dengan perlakuan pemberian (E0) dan perlakuan (E1) dan perlakuan (E2) merupakan hasil terkecil $(12,73 \mathrm{~g})$ dan perlakuan pemberian (A3) merupakan hasil yang tertingi (16,37 g) dengan bedatidak nyata dengan perlakuan lainnya dan perlakuan (A1) merupakan hasil terkecil(12,75g). Untuk lebih jelas, di bawah ini tertera Tabel 7 Rata-rata hasil berat basa akar tanaman hias lidah mertua pada umur 12 minggu.

Tabel 7. Rata-Rata Hasil Berat Basah Tanaman Lidah Mertua pada Perlakuan Ekstrak Tunas Air Kakao Umur 12 Minggu.

\begin{tabular}{llll}
\hline Perlakuan & Rata-rata & 0.05 & 0.01 \\
\hline Eo & $14,76 \mathrm{tn}$ & $\mathrm{a}$ & $\mathrm{A}$ \\
E1 & $13,76 \mathrm{tn}$ & $\mathrm{a}$ & $\mathrm{A}$ \\
E2 & $12,94 \mathrm{tn}$ & $\mathrm{a}$ & $\mathrm{A}$ \\
E3 & $15,73 \mathrm{th}$ & $\mathrm{a}$ & $\mathrm{A}$ \\
\hline
\end{tabular}

Keterangan : Angka dengan huruf yang sama pada kolom yang sama tidak berbeda nyata pada teraf $5 \%$ (huruf kecil) dan pada taraf 1\% (huruf besar) dengan uji jarak Duncan (DMRT)

Perlakuan Konsentrasi Antonik berbeda tidak nyata dengan perlakuan berbagai konsentrasi lain. Berdasarkan rata-rata perlakuan konsentrasi antonik terhadap tanaman hias lidah mertua tertinggi terdapat pada perlakuan A3 $(16,37 \mathrm{~g})$ dan yang terkecil terdapat pada perlakuan A1 (12,75g). Dapat dilihat pada Tabel 8.
Tabel 8. Rata-Rata Hasil Berat Basah Tanaman Lidah Mertuapada Perlakuan Konsentrasi Antonik pada Umur 12 Minggu.

\begin{tabular}{llll}
\hline Perlakuan & Rata-rata & 0.05 & 0.01 \\
\hline Ao & 14,12 tn & a & A \\
A1 & 12,75 tn & a & A \\
A2 & 13,97 tn & a & A \\
A3 & 16,37 tn & a & A \\
\hline
\end{tabular}

Keterangan : Angka dengan huruf yang sama pada kolom yang sama tidak berbeda nyata pada teraf $5 \%$ (huruf kecil) dan pada taraf 1\% (huruf besar) dengan uji jarak Duncan (DMRT)

\section{Berat Kering Tanaman Lidah Mertua (g)}

Data pengamatan berat kering tanaman hias lidah mertua pada umur 12 minggu dapat dilihat lebih jelas pada tabel pengukuran berat basah akar tanaman hias lidah mertua, umur 12 minggu tanaman, pengukuran menunjukan bahwa perlakuan pemberian (E0) merupakan hasil yang tertinggi $(7,75 \mathrm{~g})$ dengan tidak nyata dengan perlakuan pemberian (E2) dan perlakuan (E3) dan perlakuan (E1) merupakan hasil terkecil (5,99 g) dan perlakuan pemberian (A3) merupakan hasil yang tertingi (7,34 g) dengan bedatidak nyata dengan perlakuan lainnya dan perlakuan (A1) merupakan hasil terkecil(6,13g). Untuk lebih jelas, di bawah ini tertera Tabel 9 rata-rata hasil berat kering tanaman hias lidah mertua pada umur 12 minggu.

Tabel 9. Rata-Rata Hasil Berat Kering Tanaman Lidah Mertua pada Perlakuan Ekstrak Tunas Air Kakao Umur 12 Minggu.

\begin{tabular}{llll}
\hline Perlakuan & Rata-rata & 0.05 & 0.01 \\
\hline Eo & $7,75 \mathrm{tn}$ & $\mathrm{a}$ & $\mathrm{A}$ \\
$\mathrm{E} 1$ & $5,99 \mathrm{tn}$ & $\mathrm{a}$ & $\mathrm{A}$ \\
$\mathrm{E} 2$ & $6,50 \mathrm{tn}$ & $\mathrm{a}$ & $\mathrm{A}$ \\
$\mathrm{E} 3$ & $6.30 \mathrm{tn}$ & $\mathrm{a}$ & $\mathrm{A}$ \\
\hline Keterangan : Angka dengan huruf yang sama pada kolom yang \\
sama tidak berbeda nyata pada teraf 5\% (huruf kecil) dan pada \\
taraf 1\% (huruf besar) dengan uji jarak Duncan (DMRT)
\end{tabular}


Perlakuan Konsentrasi Antonik berbeda tidak nyata dengan perlakuan berbagai konsentrasi lain. Berdasarkan rata-rata perlakuan konsentrasi antonik terhadap tanamanhias lidah mertua tertinggi terdapat pada perlakuanA3 $(7,34 \mathrm{~g})$ dan yang terkecil terdapat pada perlakuan A1 (6,13g). Dapat dilihat pada Tabel 10.

Tabel 10. Rata-Rata Hasil Berat Kering Tanaman Lidah Mertua pada Perlakuan Konsentrasi Antonik pada Umur 12 Minggu.

\begin{tabular}{llll}
\hline Perlakuan & Rata-rata & 0.05 & 0.01 \\
\hline Ao & $6,23 \mathrm{tn}$ & $\mathrm{a}$ & $\mathrm{A}$ \\
A1 & $6,13 \mathrm{tn}$ & $\mathrm{a}$ & $\mathrm{A}$ \\
A2 & $6,83 \mathrm{tn}$ & $\mathrm{a}$ & $\mathrm{A}$ \\
A3 & $7,34 \mathrm{tn}$ & $\mathrm{a}$ & $\mathrm{A}$
\end{tabular}

Keterangan : Angka dengan huruf yang sama pada kolom yang sama tidak berbeda nyata pada teraf $5 \%$ (huruf kecil) dan pada taraf 1\% (huruf besar) dengan uji jarak Duncan (DMRT)

Volume Akar Tanaman Hias Lidah Mertua

Data pengamatan volume akar tanaman hias lidah mertua pada umur 12 minggu dapat dilihat lebih jelas pada Lampiran, tertera tabel pengukuran volume akar tanaman hias lidah mertua, umur 12 minggu tanaman, pengukuran menunjukan bahwa perlakuan pemberian (E2) merupakan hasil yang tertinggi $(3,35)$ dengantidak nyata dengan perlakuan pemberian (E1) dan perlakuan (E3)dan perlakuan (E0) merupakan hasil terkecil $(3,02)$ dan perlakuan pemberian (A3) merupakan hasil yang tertingi $(3,92)$ dengan beda tidak nyata dengan perlakuan lainnya dan perlakuan (A1) dan (A2) merupakan hasil terkecil $(2,85)$.

Untuk lebih jelas, di bawah ini tertera tabel rata-rata hasil volume akar tanaman hias lidah mertua pada umur 12 minggu.
Tabel 11. Rata-Rata Hasil Volume AkarTanaman Lidah Mertua pada Perlakuan Ekstrak Tunas Air Kakao Umur 12 Minggu.

\begin{tabular}{llll}
\hline Perlakuan & Rata-rata & 0.05 & 0.01 \\
\hline Eo & $3,02 \mathrm{tn}$ & $\mathrm{a}$ & $\mathrm{A}$ \\
E1 & $3,33 \mathrm{tn}$ & $\mathrm{a}$ & $\mathrm{A}$ \\
E2 & $3,35 \mathrm{tn}$ & $\mathrm{a}$ & $\mathrm{A}$ \\
E3 & $3,14 \mathrm{tn}$ & $\mathrm{a}$ & $\mathrm{A}$
\end{tabular}

Keterangan : Angka dengan huruf yang sama pada kolom yang sama tidak berbeda nyata pada teraf $5 \%$ (huruf kecil) dan pada taraf 1\% (huruf besar) dengan uji jarak Duncan (DMRT)

\section{Perlakuan Konsentrasi Antonik} berbeda tidak nyata dengan perlakuan berbagai konsentrasi lain. Berdasarkan rata-rata perlakuan konsentrasi antonik terhadap tanaman hias lidah mertua tertinggi terdapat pada perlakuanA3 $(196,83 \mathrm{~mm})$ dan yang terkecil terdapat pada perlakuan A2 $(166,71 \mathrm{~mm})$. Dapat dilihat pada Tabel 12 dibawah ini.

Tabel 12. Rata-Rata Hasil Volume Akar Tanaman Lidah Mertua pada Perlakuan Konsentrasi Antonik pada Umur 12 Minggu.

\begin{tabular}{llll}
\hline Perlakuan & Rata-rata & 0.05 & 0.01 \\
\hline Ao & 3,27 tn & a & A \\
A1 & 2,83 tn & a & A \\
A2 & 2,85 tn & a & A \\
A3 & 3,92 th & a & A \\
\hline
\end{tabular}

Keterangan : Angka dengan huruf yang sama pada kolom yang sama tidak berbeda nyata pada teraf $5 \%$ (huruf kecil) dan pada taraf 1\% (huruf besar) dengan uji jarak Duncan (DMRT)

Pada umur 12 minggu volume akar tanaman lidah mertua pada perlakuan antonik berpengaruh tidak nyata dari keseluruan perlakuan, sedangkan perlakuan yang tertinggi pada perlakuan A3 $(3,92)$ dan yang terendah pada perlakun A1 $(2,83)$. Seperti dijelaskan oleh Hartman dan Kester (1983) menjelaskan tujuan pemberian auksin adalah untuk mempercepat persentase setek berakar, mempercepat pemunculan akar, meningkatkan kualitas perakaran dan 
menyeragamkan muncul akar. Auksin tersebut mengaktifkan enzim-enzim tertentu untuk dapat melancarkan transportasi zat-zat organik tertentu dan ion-ion organik lain yang bermanfaat untuk mendorong reaksi biokimia dalam sel. Akibatnya akan terjadi pembelahan dan pembesaran sel diikuti oleh inisiasi akar.

\section{SIMPULAN}

Tidak adanya respon pada berat basah tanaman, bobot basah akar, bobot kering akar dan volume akar terkecuali pada parameter persentase hidup tanaman lidah mertua yaitu pada konsentrasi A1E0, A1E0 dan A2E0 memeberikan respon pada persentase hidup tanaman lidah mertua.

\section{DAFTAR PUSTAKA}

Dwidjoseputro, D.1988. Pengantar Fisiologi Tumbuhan. PT Gramedia, Jakarta.

Edmond, J. B. T. L. Senn and F. S. Andrews. 19975. F'undamentals of Holticulture. McGraw Hill Book Co. Inc New York. 476p.

Destika Cahyana. 2008 (TRUBUS, dari judul asli: "Potong Tahu Sansevieria Tembaga"/ Evy Syariefa/Peliput.

Hardjanti, S. 2005. "Pertumbuhan Setek Adenium Melalui Penganginan, Asal Bahan Setek, Penggunaan Pupuk Daun dan Komposisi Media". http:// pertanian. uns.ac.id. Diakses pada 28 Maret 2008.

Hartman, H.T dan D.E, Kester. 1983. Plant Propagation Principles and Practices Fourth Edition.Prentice-Hall, Inc. New Jersey.727p.

Juliati, ED. 2003. Hujan Emas di lapangan Sanseviera, Trubus 405 (XXXIV) 94-95.

Kusumo, S. 1984. Zat Pengatur Tumbuh Tanaman. CV.Yasaguna.

Lingga.P dan Marsono. 2006 Petunjuk Penggunaan Pupuk.Penerbit Swadaya Jakarta.

Fahrid,M, Maret 3. 2008. Generasi Baru Sanseveria.htm.

Novik Kurnianti. Pada Friday, October 18, 2013 Teknik Menanam Tanaman Hiassan sevieria.
Perum Perhutani. 1996. Pedoman Pembuatan Stek Pucuk (Tanaman Khaya anthoteca dan Swietenia Mahogoni ). Jakarta

Ponganan, A.V. 2004. Pengaruh Zat Pengatur Tumbuh NAA dan IBA terhadap Pertumbuhan Stek Mini Pule Pandak ( Rauwolfia serpentina Benth ). Hasil Kultur In Vitro. Skripsi Departemen Konservasi Sumber Daya Hutan. Fakultas Kehutanan. Institut Pertanian Bogor.

Purseglove, JW. .1975. Tropical Crops Monocotyledons, 2nd eds., Longman, London

Super-Grow. 2007. "Indole-3-Butyric Acid".

Suci, P.S. 1991. Sanseviera Si Lidah Mertua Yang Cantik, Trubus 256, Th. XXII: 116.

Syamsul.Februari 13, 2008. Sanseveria Pencetak Uang. Htm.

Sastradipradja, S. 1997. Tanaman Hias, Lembaga Biologi Nasional. LIPI, Bogor.

Sulastiana, P. 2007. Pengaruh Beberapa Konsentrasi Indol Butyric Acid (IBA) dan Pemotongan Akar pada Keberhasilan Aklimatisasi Sanseviera trifasciata Menggunakan 2 Media Tanam. Skripsi. Fakultas Pertanian. Universitas Lampung. 72 halaman.

Salisbury B.F dan C.W Ross. 1995. Fisiologi Tumbuhan. Diterjemahkan oleh Diah R. Lukman dan Ir. Sumaryono, M.Sc. Jilid 3. ITB. Bandung. 343 halaman.

Sri Rahmayani. 2007. Respon Pertumbuhan Stek Lidah Mertua Sanseviera trifasciataPada Pemberian IBA dan Asal Bahan Tanam. Skripsi. Fakultas Pertanian. UNILA.

Tjitrosopomo, Gembong, 1988, Taksonomi Tumbuhan ( Sepermathopyta ) Yogyakarta : Universitas Gadjah Mada.

Vessey, J. K. 2003. Plant growth promoting rhizobacteria as bio fertilizers. J. Plant Soil : 255- 586

Weaver, R. J. 1983. Plant Growth Substances in Agriculture. W. H. Freeman Co. San Fransisco. Pp 119-131.

Wuryan.Januari 8.2009. Kemampuan Generasi Daun pada Tanaman Sanseveria yang Berdaun Varigata.

Yasman, I dan W.T.M. Smits, 1988. Metode Pembuatan Stek Dipterocarpaceae. Balai Penelitian Kehutanan Samarinda.

Zaerr, J.B. dan M.O. Mapes. $1982 . \quad$ Actions of Growth Regulators dalam tissue Culture inForestriEdited by J. M. Bonga dan D.J. Durzan. Matinus Nijhoff/DR. W. Junk Publisher. Boston. 